\title{
La administración de pruebas diagnósticas en pacientes con baja probabilidad de enfermedad grave produce un insuficiente efecto tranquilizador
}

\author{
The administration of diagnostic tests in patients with low probability of severe disease produces an
} insufficient calming effect

\section{Objetivos}

Analizar el efecto de administrar pruebas diagnósticas en pacientes con una baja probabilidad de desarrollar una enfermedad grave en cuanto a preocupación del paciente sobre la enfermedad, ansiedad, persistencia de los síntomas y utilización de recursos sanitarios.

Fuente de datos, selección de estudios y extracción de datos.

La búsqueda abarcó MEDLINE, the Cochrane Central Register of Controlled Trials, EMBASE, PsychINFO, CINAHL, y ProQuest Dissertations. Se incluyeron ensayos clínicos aleatorizados publicados hasta diciembre de 2011 realizados en pacientes mayores de 18 años con síntomas de baja probabilidad de enfermedad grave, cuyas pruebas iniciales diagnósticas (imágenes, endoscopías o pruebas cardíacas) se realizaron en atención primaria (AP) o secundaria. Los grupos control recibieron la atención habitual o tratamiento empírico. Se excluyeron aquellos artículos realizados en centros de atención terciaria, donde la prevalencia de enfermedades graves es más elevada. Las variables estudiadas fueron: preocupación
Rolfe A, y Col. JAMA Intern Med. 2013;173(6):407-16. por la enfermedad, ansiedad, cambios en el síntoma original y visitas posteriores al médico.

\section{Resultados}

Se seleccionaron 14 estudios (3.828 pacientes), nueve realizados en el marco de AP y cinco en medicina interna. Ocho estudios incluyeron pruebas diagnósticas para dispepsia (endoscopia o radiología), tres estudiaron el dolor de espalda con radiología, uno incluyó analítica sanguínea y electrocardiografía para el dolor torácico, y dos estudiaron palpitaciones y cefalea con resonancia magnética y holter electrocardiográfi$\mathrm{co}$, respectivamente. Las variables se estudiaron a corto $(<3$ meses) y largo plazo (> 3 meses).

Se objetivó un nivel alto de heterogeneidad entre los ensayos. El resumen de los principales resultados del metanálisis se observan en la tabla 1.

Aunque existe una reducción en el número de consultas posteriores a los centros de AP, la reducción es mínima, ya que para evitar una consulta de dispepsia, se deben realizar 16 endoscopias, y para evitar una consulta por lumbalgia, hay que irradiar a 26 pacientes.

Tabla 1. Resumen de los principales resultados del metanálisis

\begin{tabular}{|c|c|c|c|}
\hline Variables estudiadas & $\begin{array}{l}\text { Tiempo de evolución } \\
\text { (N } \text { de estudios) }\end{array}$ & OR (IC 95\%) & Heterogeneidad ${ }^{\star}$ (12) \\
\hline \multirow[t]{2}{*}{ Preocupación por la enfermedad } & $<3$ meses $(2)$ & $0,90(0,31$ a 1,77$)$ & $0 \%$ \\
\hline & $>3$ meses (3) & $0,87(0,55$ a 1,39$)$ & $0 \%$ \\
\hline \multirow[t]{2}{*}{ Ansiedad } & $<3$ meses $(2)$ & $0,06(-0,16 \text { a } 0,28)^{* *}$ & $0 \%$ \\
\hline & $>3$ meses $(2)$ & $0,21(-0,02 \text { a } 0,44)^{* *}$ & $0 \%$ \\
\hline \multirow[t]{2}{*}{ Persistencia de los síntomas } & $<3$ meses $(6)$ & $0,92(0,6$ a 1,41$)$ & $67 \%$ \\
\hline & $>3$ meses $(10)$ & $0,99(0,85$ a 1,15$)$ & $0 \%$ \\
\hline Uso de Recursos Sanitarios & Sin definir (9) & $0,77(0,62$ a 0,96$)$ & $33 \%$ \\
\hline \multicolumn{2}{|c|}{$\begin{array}{l}\text { Conclusiones } \\
\text { Ante la presencia de una sintomatología concreta en pacientes } \\
\text { con un riesgo bajo de desarrollar una enfermedad, las pruebas } \\
\text { diagnósticas no parecen confortar a los pacientes, disminuir su } \\
\text { ansiedad ni resolver sus síntomas en el corto o en el largo }\end{array}$} & \multicolumn{2}{|c|}{$\begin{array}{l}\text { plazo. Se necesitan más estudios para aumentar la certeza de } \\
\text { las pruebas médicas necesarias y desarrollar estrategias de } \\
\text { seguridad para el manejo de pacientes sin pruebas, cuando un } \\
\text { resultado anormal es poco probable. } \\
\text { Fuente de financiamiento: no referida }\end{array}$} \\
\hline \multicolumn{4}{|l|}{ Comentario } \\
\hline \multicolumn{2}{|c|}{$\begin{array}{l}\text { Los problemas derivados de la utilización de pruebas diagnósticas, al } \\
\text { igual que sucede con el cuidado médico en general, pueden clasificarse } \\
\text { en tres grupos según el uso que se hace de dichas pruebas: infrauti- } \\
\text { lización (no se realiza una determinación diagnóstica concreta que } \\
\text { habría producido un resultado favorable para el paciente), sobreuti- } \\
\text { lización (ocurre cuando la determinación se realiza en determinadas cir- } \\
\text { cunstancias en las que el daño potencial excede al posible beneficio) y } \\
\text { mala utilización (se ha seleccionado una determinación diagnóstica } \\
\text { adecuada, pero ocurre una complicación que conduce a que el paciente } \\
\text { no reciba todo el beneficio que debiera'. Desde esta perspectiva, el indi- } \\
\text { viduo sano convertido en enfermo imaginario se convertirá en usuario } \\
\text { habitual con las consecuencias que implica a nivel individual y al propio } \\
\text { sistema sanitario. Actualmente, las habilidades tradicionales del médico, } \\
\text { basadas en el trato personal y en la entrevista clínica, parecen ser rele- } \\
\text { gadas a causa de la confianza que generan las nuevas tecnologías }{ }^{23} \text {. }\end{array}$} & \multicolumn{2}{|c|}{$\begin{array}{l}\text { Conclusiones del Comentador } \\
\text { Los médicos de AP a menudo solicitamos pruebas diagnósticas a } \\
\text { pacientes con baja probabilidad de desarrollar una enfermedad grave, } \\
\text { con un fin tranquilizador y de exclusión de patologías. Esta opción } \\
\text { parece más objetiva que una simple entrevista clínica. Raramente se } \\
\text { cree tener certeza médica hasta que se han obtenido todos los resulta- } \\
\text { dos. Pero resulta importante considerar los efectos adversos de las } \\
\text { pruebas diagnósticas, los falsos positivos y negativos, el incremento en } \\
\text { el costo sanitario, el aumento de procedimientos diagnósticos frecuente- } \\
\text { mente invasivos y los efectos en la ansiedad e incertidumbre del } \\
\text { paciente que ellos ocasionan. En nuestra práctica cotidiana debemos } \\
\text { replanteamos el valor de las pruebas diagnósticas según el motivo de } \\
\text { su pedido, las alternativas de tratamiento disponibles, junto a las expec- } \\
\text { tativas y deseos del paciente. }\end{array}$} \\
\hline
\end{tabular}

Gustavo Giménez Lascano [ Médico de Familia. Director de la Diplomatura Universitaria de Medicina Familiar de la Universidad del Norte Santo Tomas de Aquino (UNSTA). ggimenezlascano@yahoo.com.ar]

Giménez Lascano G. La administración de pruebas diagnósticas en pacientes con baja probabilidad de enfermedad grave produce un insuficiente efecto tranquilizador. Evid Act Práct Ambul. 2014, 17(2). Abr-Jun. 61. Comentado de: Rolfe Ay Col. Reassurance after diagnostic testing with a low pretest probability of serious disease. JAMA Intern Med. 2013;173(6):407-16. PMID: 23440131.

\section{Referencias}

1. Chassin MR, Galvin RW. The urgent need to improve health care quality. Institute of Medicine National Roundtable on Health Care Quality. JAMA. 1998; 280:1000-5.

2. Van Walraven C, y Col. Effect of population-based interventions on laboratory utilization: a time-series analysis. JAMA. 1998;280:2028-33.

3. Gialamas A, y Col investigating tiredness in Australian general practice. Do pathology tests help in diagnosis? Aust Fam Physician. 2003; 32(8):663-6. 